\title{
Sleep-Disordered Breathing - a Real Therapeutic Target for Hypertension, Pulmonary Hypertension, Ischemic Heart Disease, and Chronic Heart Failure?
}

\author{
Takaaki Nakamoto
}

Dokkyo Medical University Nikko Medical Center

\begin{abstract}
Sleep-disordered breathing (SDB) is a risk factor for cardiovascular disease including acute coronary syndrome and acute myocardial infarction, and treating SDB prevents their development and recurrence and improves a patient's prognosis. Therefore, SDB is considered a therapeutic target for cardiovascular disease. In 2010, the Japanese Circulation Society published guidelines for the diagnosis and treatment of SDB in patients with cardiovascular disease. However, therapeutic intervention for patients with SDB was recently reported not to suppress the development or deterioration of cardiovascular disease in three middle- to large-sized randomized clinical trials: the SERVE-HF trial, which examined the effects of adaptive servo-ventilation (ASV) on patients with chronic heart failure (CHF) and central sleep apnea; the CAT-HF trial, which examined the effects of ASV therapy on patients with CHF after acute deterioration; and the SAVE study, which examined the secondary preventive effect of continuous positive airway pressure (CPAP) on patients with ischemic heart disease who had mild to moderate obstructive sleep apnea. These studies caused hesitation among clinicians to proactively treat SDB by ASV or CPAP therapy. The present review is focused on hypertension, pulmonary hypertension, ischemic heart disease, and CHF to newly summarize the studies available to date from the viewpoints of epidemiology, pathogenesis, and treatment. I expect this review be informative and useful for physicians who treat patients with SDB by CPAP or ASV therapy in the clinical setting. (J Nippon Med Sch 2018; 85: 70-77)
\end{abstract}

Key words: sleep-disordered breathing, hypertension, pulmonary hypertension, ischemic heart disease, chronic heart failure

\section{Introduction}

Sleep-disordered breathing (SDB) is a risk factor for cardiovascular disease $\mathrm{e}^{1-7}$, and several clinical studies have shown that the treatment of SDB prevents its development and recurrence and improves the patient's progno$\operatorname{sis}^{7-9}$. Therefore, the understanding that SDB is a therapeutic target for cardiovascular disease has grown rapidly since the year 2000. In 2010, the Japanese Circulation Society published guidelines for the diagnosis and treatment of SDB in patients with cardiovascular disease (JCS 2010 ${ }^{10}$. However, three middle- to large-sized randomized clinical trials ${ }^{11-13}$ have shown that therapeutic intervention for patients with SDB did not suppress the development or deterioration of cardiovascular disease. The first of the studies was the SERVE-HF trial, which examined the effects of adaptive servo-ventilation (ASV) on patients with chronic heart failure (CHF) that was complicated by central sleep apnea (CSA); the study attracted much attention because of having suggested an increased cardiovascular mortality, though ASV therapy improved SDB compared with no provision of treatment ${ }^{11}$. The second of the studies was the CAT-HF trial, which examined the effects of ASV therapy on patients with CHF after acute deterioration; the study was discontinued due to the reported outcomes from the SERVE-HF trial, and its results were analyzed under the situation that the target number of patients was not reached ${ }^{12}$. Consequently, ASV therapy showed no significant effect on patients with CHF. The third of the studies was the SAVE study, which examined the secondary preventive effect of continuous positive airway pressure (CPAP) on patients with ischemic heart disease who had mild to moderate ob-

Correspondence to Takaaki Nakamoto, MD, PhD, FAHA, FCCP, Dokkyo Medical University Nikko Medical Center, 632 Takatoku, Nikko, Tochigi 321-2593, Japan

E-mail: takanaka@dokkyomed.ac.jp

Journal Website (http://www2.nms.ac.jp/jnms/) 
structive sleep apnea (OSA); the study did not show any secondary preventive effect of usual care plus CPAP therapy compared with usual care alone ${ }^{13}$.

These studies caused hesitation among clinicians to proactively treat SDB by ASV or CPAP therapy. The present review is focused on hypertension, pulmonary hypertension, ischemic heart disease, and CHF to newly summarize the studies available to date from the viewpoints of epidemiology, pathogenesis, and treatment. I expect this review be informative and useful for physicians in the clinical setting.

The diagnostic criteria and severity classification of SDB are defined by the International Classification of Sleep Disorders (ICSD) published by the American Academy of Sleep Medicine (currently, the third edition) ${ }^{14}$, and both the JCS $2010^{10}$ and the guidelines published by the SDB Study Group are nearly in line with the ICSD.

\section{Hypertension}

\section{Epidemiology}

SDB of patients with hypertension mainly consists in OSA during which upper airway obstruction reduces or transiently halts airflow and respiratory efforts in the thoracoabdominal region. OSA is considered to coexist in $30 \%$ of patients with hypertension ${ }^{15,16}$. Moreover, the prevalence of SDB is very high $(80 \%)$ in patients with drug-resistant hypertension ${ }^{17}$.

\section{Pathogenesis}

Upper airway obstruction, which causes OSA in many patients with hypertension, is determined by morphological factors (e.g., small cross-section of the airways) and functional factors that are balanced between the tension of the upper airway dilators and the negative pressure of the airway lumen ${ }^{10}$. OSA causes the hyperactivity of the sympathetic nervous system and increases the activity of the renin-angiotensin-aldosterone (RAA) system through the frequent provocation of arousal responses and the intermittent development of hypoxemia and hypercapnia ${ }^{18-21}$; thus, OSA is known to be involved in the induction and deterioration of hypertension (Fig. 1). An association between sleep apnea syndrome assessed with apnea-hypopnea index (AHI) and the development of hypertension has been found ${ }^{3}$. In addition, OSA is associated with the development of nocturnal hypertension and nondipper hypertension ${ }^{21}$ and is known to precede nondipper hypertension ${ }^{22}$. Hence, the Guidelines for the Management of Hypertension in Japan ${ }^{23}$ recognize the following: 1) OSA does not originate from hypertension but is a risk factor for the induction and deterioration of hypertension; and 2) it is essential to adequately diagnose and treat OSA in patients with hypertension. In particular, OSA is the most common factor for secondary hy-

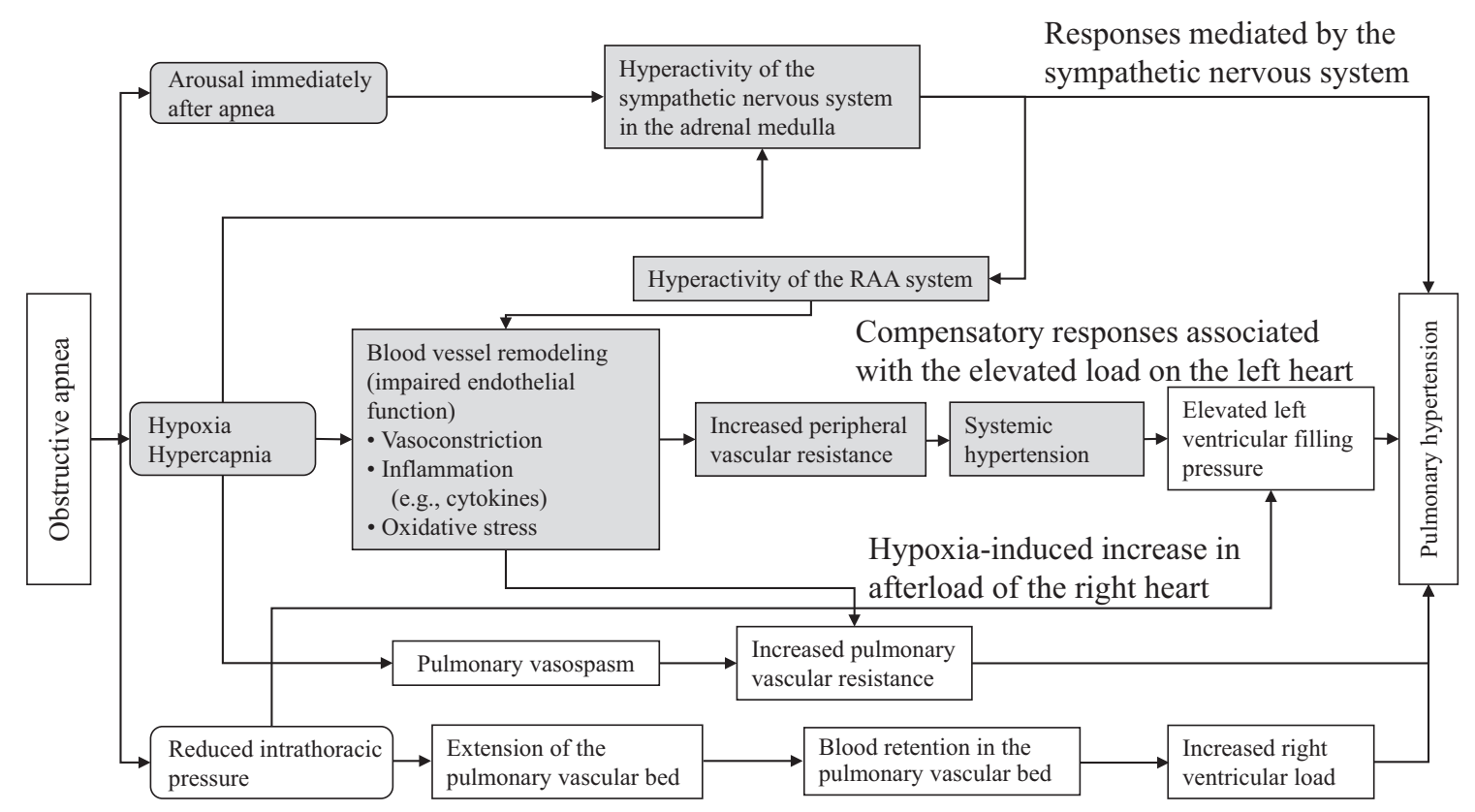

Increased preload of the right heart due to increased venous return

Fig. 1 Putative pathophysiologic mechanisms of obstructive sleep apnea in patients with hypertension or pulmonary hypertension Gray shaded area: Occurs also in hypertension. RAA, renin-angiotensin-aldosterone 
pertension in patients with resistant hypertension ${ }^{24}$. Therefore, physicians should actively suspect the presence of OSA and conduct a sleep test.

\section{Treatment}

The obesity-induced deposition of fat in upper airway soft tissue is considered to be the most important risk factor for OSA. Therefore, weight reduction should be attempted first in the treatment of OSA. However, obese patients are not necessarily predominant among Japanese patients with OSA. Hence, the morphology of the cranial and facial bones, especially the small size of the mandible, is considered to be an important factor. The treatment of choice for patients with moderate or severe OSA is CPAP therapy ${ }^{10}$. CPAP therapy delivers air via a nasal or oro-nasal mask to resolve the stenosis or obstruction of the upper airways by making their pressure positive. Several meta-analyses of randomized controlled clinical trials of CPAP therapy in patients with OSA have shown that the therapy can decrease systolic blood pressure and diastolic blood pressure by 2 to $2.5 \mathrm{mmHg}$ and 1.5 to 2 $\mathrm{mmHg}$, respectively, in patients with hypertension. CPAP therapy showed a more marked hypotensive effect on patients with refractory hypertension and recovered nocturnal blood pressures in patients with nondipper hypertension ${ }^{25}$. A linear correlation between the duration of CPAP therapy and decreases in blood pressures was reported in patients with refractory hypertension (1.9- and 1.0-mmHg decreases in SBP and DBP, respectively, per 1 hour of CPAP therapy ${ }^{26}$. CPAP therapy was associated with a lower risk of hypertension ${ }^{27,28}$. The minimum threshold duration of CPAP therapy per night to obtain the hypotensive effect is considered to be 4 hours $^{25,29,30}$, with the optimal duration being 5 to 6 hours $^{24}$. In clinical practice, many physicians consider that CPAP therapy is difficult to initiate or continue. In the clinical settings, for example, physicians would be concerned about how to adequately set the initial pressures for CPAP therapy and what should be done to motivate patients to continue with the therapy. In my experience, however, the initial setting of pressures for CPAP therapy is acceptable for many patients because the mode of automatic pressure change-which is provided in recently marketed respirators-varies pressures on an as-needed basis. The upper limit for pressures may be useful when patient adherence is poor. Fitting of the mask is more important than pressures for CPAP therapy. At the time of initiating CPAP therapy, it is critically important to select a mask that fits to the contours of the patient's face and to instruct the patient how to adequately wear the mask (i.e., to make the patient realize the importance of not fastening the fixing band of the mask too tightly). For the objective of encouraging the patient to continue with CPAP therapy, furthermore, it is important that the attending physician verifies in the outpatient service whether the patient is using the device appropriately in an attempt to prevent a decline in the patient's motivation to continue with the therapy.

\section{Pulmonary Hypertension}

\section{Epidemiology}

A cross-sectional observational study of 220 patients with OSA who had an AHI > 20 events/hour revealed the presence of pulmonary hypertension (average pulmonary arterial pressure: $>20 \mathrm{mmHg}$ ) in $17 \%$ of patients ${ }^{27}$. Thus, patients with OSA are known to be frequently affected with pulmonary hypertension. Secondary pulmonary hypertension due to SDB is listed in Group III of the clinical classifications of hypertension in the Guidelines for the Treatment of Pulmonary Hypertension in Japan (JCS 2012) $)^{29}$.

\section{Pathogenesis}

OSA is one of the etiologies of pulmonary hypertension. Similar to hypertension, therefore, not only hypoxia and frequent arousal but also decreased intraperitoneal pressure is included in the putative pathophysiologic mechanisms (Fig. 1) ) $^{10,31-33}$.

\section{Treatment}

The treatment of first choice is CPAP therapy when OSA causes secondary pulmonary hypertension. The treatment of OSA by CPAP therapy is known to lower pulmonary arterial pressure at the time of arousal during the daytime ${ }^{34-36}$. However, CPAP therapy is not indicated for events other than secondary pulmonary hypertension caused by hypoxia. Due to the possibility that positive airway pressure increases pulmonary blood vessel resistance, CPAP therapy cannot be recommended for patients with Group I pulmonary artery hypertension or Group IV chronic thromboembolic pulmonary hypertension that are defined in the Guidelines for the Treatment of Pulmonary Hypertension in Japan (appropriate pharmacotherapy and oxygenation therapy are selected in these patients). Since CPAP therapy cannot be sweepingly considered as a recommended choice for the treatment of pulmonary hypertension, it is therefore mandatory to precisely specify the cause(s) of pulmonary hypertension. 


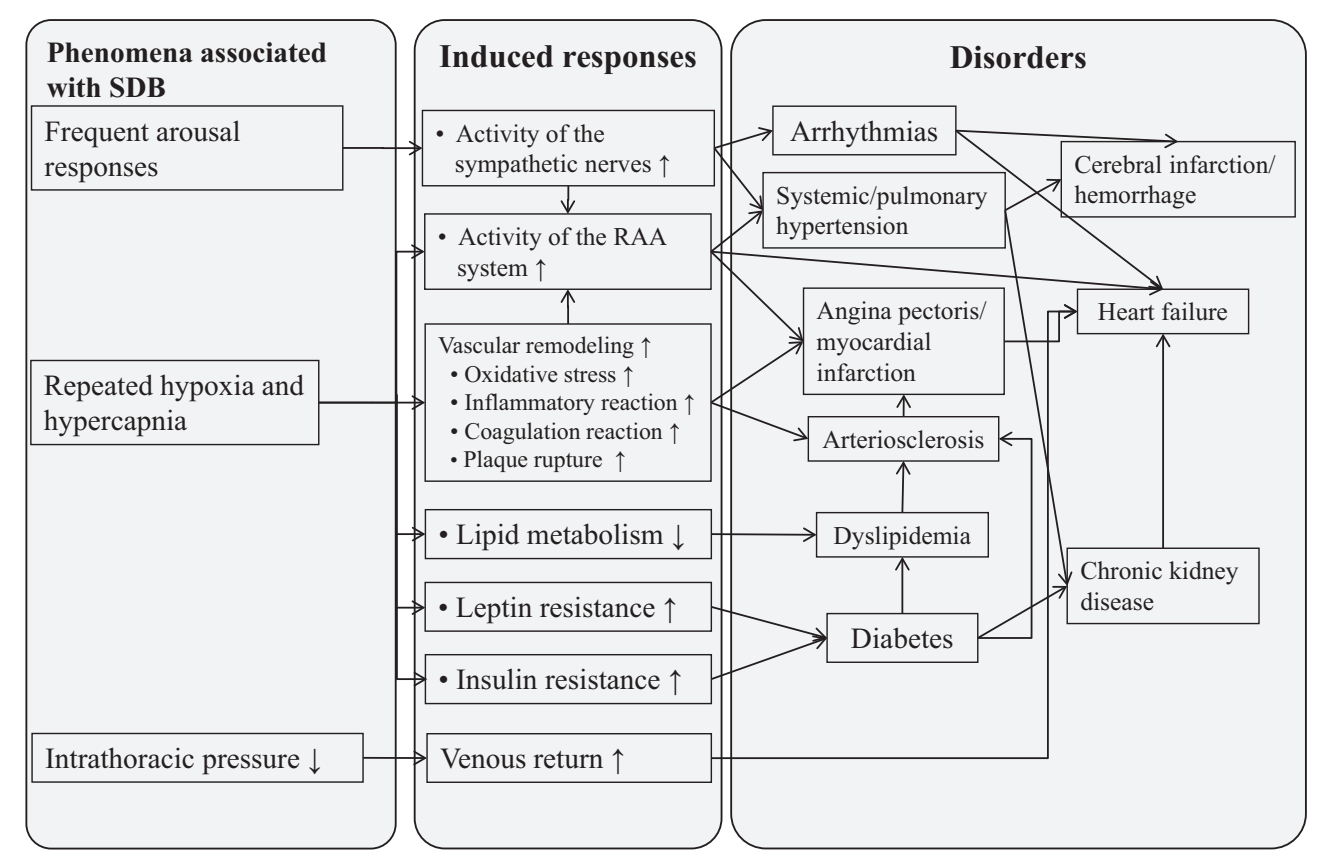

Fig. 2 Putative pathophysiologic mechanisms of sleep-disordered breathing in patients with cardiovascular disease including ischemic heart disease

$\mathrm{SDB}$, sleep-disordered breathing; RAA, renin-angiotensin-aldosterone

\section{Ischemic Heart Disease}

\section{Epidemiology}

OSA frequently coexists in patients with coronary artery disease or acute coronary syndromes ${ }^{37,38}$. The risk of developing ischemic heart disease is 1.2 to 6.9 times greater in patients with OSA than in healthy individuals. Fatal and nonfatal cardiovascular events were 2.87 and 3.17 times more frequent, respectively, in patients with severe OSA who had an AHI of 30 events/hour than in healthy individuals ${ }^{7}$.

\section{Pathogenesis}

OSA is a risk factor for ischemic heart disease. SDBinduced intermittent hypoxia is known to be associated with glucose intolerance independent of age, sex, body mass index, and abdominal circumference ${ }^{38}$. Similar to ischemia-reperfusion injury, moreover, intermittent hypoxia is considered to increase the risk of developing ischemic heart disease by decreasing the endothelial function of the coronary arteries through inflammation and free radicals (Fig. 2) ${ }^{39}$.

\section{Treatment}

CPAP therapy is the treatment of choice for patients with severe OSA, as for patients with other cardiovascular disease. The incidence of cardiovascular events decreased to the level found in healthy individuals when CPAP therapy was conducted in patients with OSA who had an AHI >30 events/hour ${ }^{7}$, which led to the understanding that the treatment of patients with severe OSA is effective for the primary prevention of cardiovascular disease $^{10}$. As described in the first paragraph of this article, however, the SAVE study showed that CPAP therapy does not have any secondary preventive effect on cardiovascular disease and appears to indicate that CPAP therapy for the secondary prevention of cardiovascular disease is meaningless. However, attention should be paid to the facts that the SAVE study ${ }^{13}$ excluded patients with severe SDB who had an AHI >30 events/hour and patients whose $\mathrm{SaO}_{2}$ was lowered by SDB, in addition to: 1) concern about the maintenance of treatment level among the study sites and 2) the issue that the average duration of CPAP therapy was less than 4 hours. The SAVE study excluded patients who should undergo CPAP therapy and examined patients with milder OSA. Furthermore, the patients in the RICCADSA randomized controlled trial in coronary artery disease who had no daytime sleepiness showed a cardiovascular risk reduction not in the study population but in a subgroup of patients who underwent $\geq 4$-hour CPAP therapy ${ }^{40}$. Therefore, I consider that CPAP therapy requires a minimum of 4 hours to exert a risk-reducing effect in patients with hypertension or cardiovascular disease. In light of my consideration, the SAVE study does not negate the conventional therapeutic strategy for patients with SDB. At my institution, we routinely conduct pulse oximetry as the first step before hospitalization to screen patients with ischemic heart disease for the presence or absence of intermittent hypoxia dur- 


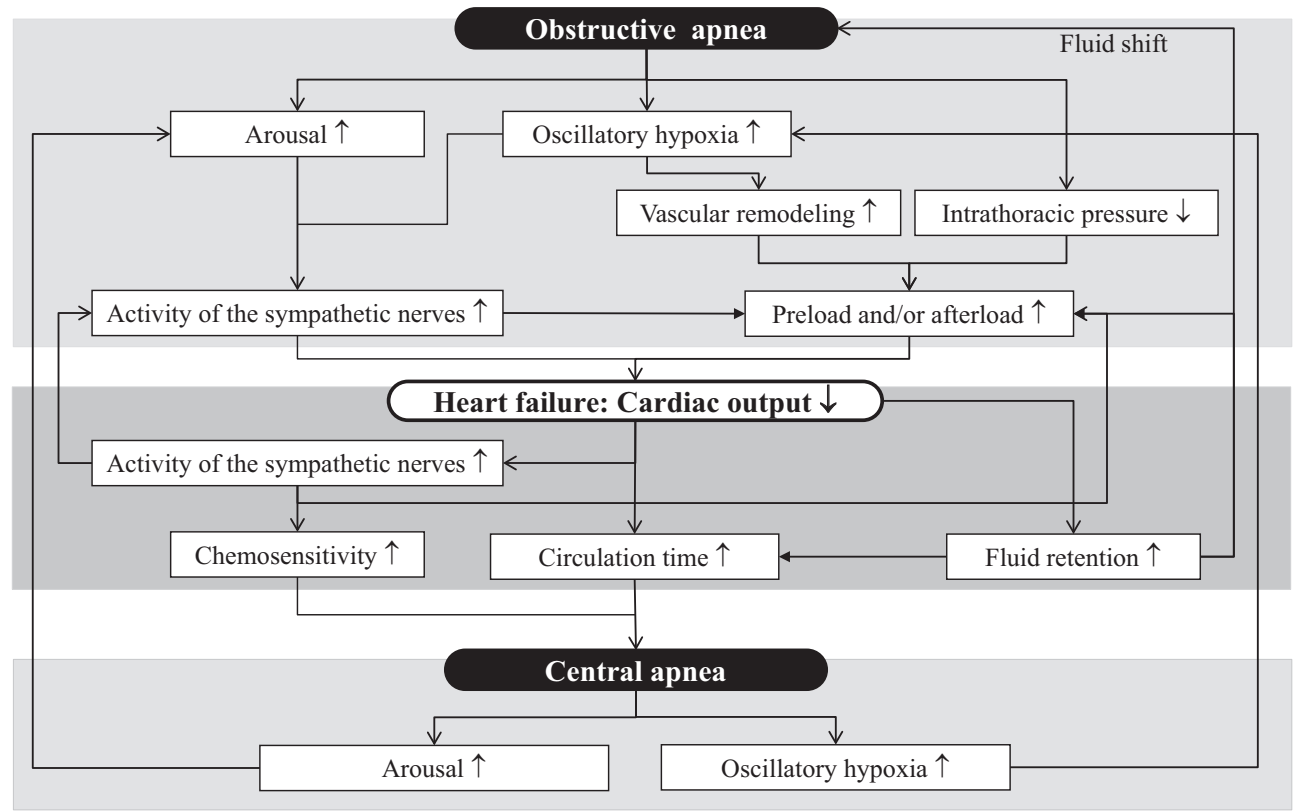

Fig. 3 Putative pathophysiologic mechanisms of sleep-disordered breathing and central apnea in patients with chronic heart failure

ing sleep; subsequently, we determine the further need to conduct a sleep test and begin treatment.

\section{Chronic Heart Failure}

\section{Epidemiology}

SDB of patients with CHF is featured by not only OSA, but also Cheyne-Stokes respiration (CSR-CSA), a type of CSA that is devoid of respiratory efforts in the thoracoabdominal region due to the suspension of respiratory stimuli from the central nervous system ${ }^{41}$. OSA and CSRCSA were respectively found in 11 to $37 \%$ and 29 to $40 \%$ of patients who had heart failure with a reduced ejection fraction $(\mathrm{HFrEF})^{4,42-45}$. SDB was found in $55 \%$ of a small number of patients who had heart failure with a preserved ejection fraction $(\mathrm{HFpEF})^{45}$.

\section{Pathogenesis}

OSA is considered to be one of the etiologies of heart failure $^{46}$. In patients with heart failure, furthermore, socalled "fluid shift," by which body fluids that are retained due to heart failure move to the craniocervical region, is provoked or aggravated by OSA ${ }^{47}$. On the other hand, CSR-CSA occurs as a consequence of heart failure and when both of the following phenomena associated with heart failure progression-enhanced chemosensitivity and delayed circulation (i.e., low cardiac output)-appear (Fig. 3) ${ }^{48}$. Overnight fluid shift to the craniocervical region may also contribute to the pathogenesis of $\mathrm{CSA}^{50}$. Similar to OSA, furthermore, CSR-CSA is also considered as a prognosticator because of repeatedly causing hy- poxia and arousal ${ }^{45,49}$. Meanwhile, however, the SERVEHF trial indicated that CSR-CSA might increase cardiac output in patients with chronic heart failure. Therefore, CSR-CSA is now under review as to its pathophysiologic role- "friend" or "foe"-in this patient population ${ }^{51}$.

\section{Treatment}

In patients with OSA, CPAP therapy improves not only SDB, but also sympathetic nerve activity ${ }^{52}$ and the left ventricular ejection fraction ${ }^{53}$. The successful maintenance of CPAP compliance improved the prognosis of patients with heart failure . $^{54}$

In patients with CHF involving CSR-CSA, on the other hand, treatment with an artificial respirator that maintains the volume of ventilation constant in response to the volume of spontaneous respiration, that is ASV therapy, is being attempted, in addition to nocturnal oxygenation therapy and CPAP therapy. Randomized controlled clinical trials have been conducted for all of these therapeutic modalities. However, these modalities have not shown any definite effect on disease prognosis, although have shown a certain level of effect on improving cardiac function and symptoms ${ }^{11,12,55-57}$. As described previously, the mortality rate increased significantly in patients with HFrEF who had CSR-CSA-dominant SDB in the ASV group of the SERVE-HF triall'. In the CAT-HF trial as well, ASV showed no prognosis-improving effect on patients with HFrEF, although it did show a tendency to improve disease prognosis in patients with $\mathrm{HFpEF}^{12}$. CPAP therapy and ASV therapy reduce the transmural 
pressure of the left ventricle and venous return through positive airway pressure ${ }^{58,59}$. However, low cardiac output frequently occurs in patients with CHF and CSR-CSA ${ }^{44}$. CPAP therapy and ASV therapy reduce venous return through positive airway pressure in patients with preserved preload reserve, but they also reduce preload pressure and lower cardiac output. Excessive positive pressures were applied to treat some patients with SDB in both the SERVE-HF trial and the CAT-HF trial, which probably masked the patient prognosis- and cardiac function-improving effects of ASV therapy. Therefore, cardiologists should fully examine whether positive ventilation therapy adversely affects the hemodynamics of patients with $\mathrm{CHF}$ when conducting CPAP or ASV therapy and should then initiate and manage the therapy appropriately.

In Japan, the Japanese Circulation Society and the Japanese Heart Failure Society announced a joint statement for the proper use of ASV in patients with heart failure $^{60}$. Readers are invited to read the statement for reference.

Acknowledgments: The author is grateful to Satoshi Sakima, $\mathrm{MD}$, for valuable discussion about the manuscript.

Conflict of Interest: The present article was prepared with funding from TEIJIN PHARMA Limited.

\section{References}

1. Shahar E, Whitney CW, Redline S, Lee ET, Newman AB, Nieto FJ, O'Connor GT, Boland LL, Schwartz JE, Samet JM: Sleep-disordered breathing and cardiovascular disease: cross-sectional results of the Sleep Heart Health Study. Am J Respir Crit Care Med 2001; 163: 19-25.

2. Nieto FJ, Young TB, Lind BK, Shahar E, Samet JM, Redline S, D'Agostino RB, Newman AB, Lebowitz MD, Pickering TG: Association of sleep-disordered breathing, sleep apnea, and hypertension in a large community-based study. Sleep Heart Health Study. JAMA 2000; 283: 18291836.

3. Peppard PE, Young T, Palta M, Skatrud J: Prospective study of the association between sleep-disordered breathing and hypertension. N Engl J Med 2000; 342: 1378-1384.

4. Wang $\mathrm{H}$, Parker JD, Newton GE, Floras JS, Mak S, Chiu KL, Ruttanaumpawan P, Tomlinson G, Bradley TD: Influence of obstructive sleep apnea on mortality in patients with heart failure. J Am Coll Cardiol 2007; 49: 1625-1631.

5. Mehra R, Benjamin EJ, Shahar E, Gottlieb DJ, Nawabit R, Kirchner HL, Sahadevan J, Redline S: Sleep Heart Health Study: Association of nocturnal arrhythmias with sleepdisordered breathing: The Sleep Heart Health Study. Am J Respir Crit Care Med 2006; 173: 910-916.

6. Mooe T, Rabben T, Wiklund U, Franklin KA, Eriksson P: Sleep-disordered breathing in men with coronary artery disease. Chest 1996; 109: 659-663.

7. Marin JM, Carrizo SJ, Vicente E, Agusti AG: Long-term cardiovascular outcomes in men with obstructive sleep apnoea-hypopnoea with or without treatment with continuous positive airway pressure: an observational study. Lancet 2005; 365: 1046-1053.

8. He J, Kryger MH, Zorick FJ, Conway W, Roth T: Mortality and apnea index in obstructive sleep apnea. Experience in 385 male patients. Chest 1988; 94: 9-14.

9. Marti S, Sampol G, Muñoz X, Torres F, Roca A, Lloberes P, Sagalés T, Quesada P, Morell F: Mortality in severe sleep apnoea/hypopnoea syndrome patients: impact of treatment. Eur Respir J 2002; 20: 1511-1518.

10. JCS Joint Working Group: Guidelines for diagnosis and treatment of sleep disordered breathing in cardiovascular disease (JCS 2010). Circ J 2010; 74 Suppl II: 963-1051.

11. Cowie MR, Woehrle H, Wegscheider K, Angermann C, d'Ortho MP, Erdmann E, Levy P, Simonds AK, Somers VK, Zannad F, Teschler H: Adaptive servo-ventilation for central sleep apnea in systolic heart failure. $\mathrm{N}$ Engl J Med 2015; 373: 1095-1105.

12. O'Connor CM, Whellan DJ, Fiuzat M, Punjabi NM, Tasissa G, Anstrom KJ, Benjafield AV, Woehrle H, Blase AB, Lindenfeld J, Oldenberg O: Cardiovascular Outcomes With Minute Ventilation-Targeted Adaptive ServoVentilation Therapy in Heart Failure: The CAT-HF Trial. J Am Coll Cardiol 2017; 69: 1577-1587.

13. McEvoy RD, Antic NA, Heeley E, Luo Y, Ou Q, Zhang X, Mediano O, Chen R, Drager LF, Liu Z, Chen G, Du B, McArdle N, Mukherjee S, Tripathi M, Billot L, Li Q, Lorenzi-Filho G, Barbe F, Redline S, Wang J, Arima H, Neal B, White DP, Grunstein RR, Zhong N, Anderson CS; SAVE Investigators and Coordinators: CPAP for prevention of cardiovascular events in obstructive sleep apnea. N Engl J Med 2016; 375: 919-931.

14. American Academy of Sleep Medicine: International classification of sleep disorders, 3rd ed.: Diagnostic and coding manual, 2014; American Academy of Sleep Medicine.

15. Kales A, Bixler EO, Cadieux RJ, Schneck DW, Shaw LC 3rd, Locke TW, Vela-Bueno A, Soldatos CR: Sleep apnoea in a hypertensive population. Lancet 1984; 2: 1005-1008.

16. Somers VK, White DP, Amin R, Abraham WT, Costa F, Culebras A, Daniels S, Floras JS, Hunt CE, Olson LJ, Pickering TG, Russell R, Woo M, Young T; American Heart Association Council for High Blood Pressure Research Professional Education Committee, Council on Clinical Cardiology; American Heart Association Stroke Council; American Heart Association Council on Cardiovascular Nursing; American College of Cardiology Foundation: Sleep apnea and cardiovascular disease: an American Heart Association/American College Of Cardiology Foundation Scientific Statement from the American Heart Association Council for High Blood Pressure Research Professional Education Committee, Council on Clinical Cardiology, Stroke Council, and Council On Cardiovascular Nursing. In collaboration with the National Heart, Lung, and Blood Institute National Center on Sleep Disorders Research (National Institutes of Health): Sleep apnea and cardiovascular disease. Circulation 2008; 118: 1080-1111.

17. Logan AG, Perlikowski SM, Mente A, Tisler A, Tkacova $R$, Niroumand M, Leung RS, Bradley TD: High prevalence of unrecognized sleep apnoea in drug-resistant hypertension. J Hypertens 2001; 19: 2271-2277.

18. Dimsdale JE, Coy T, Ziegler MG, Ancoli-Israel S, Clausen $\mathrm{J}$ : The effect of sleep apnea on plasma and urinary catecholamines. Sleep 1995; 18: 377-381.

19. Narkiewicz K, van de Borne PJ, Cooley RL, Dyken ME, 
Somers VK: Sympathetic activity in obese subjects with and without obstructive sleep apnea. Circulation 1998; 98: 772-776.

20. Jin ZN, Wei YX: Meta-analysis of effects of obstructive sleep apnea on the renin-angiotensin-aldosterone system. J Geriatr Cardiol 2016; 13: 333-343.

21. Kario K: Obstructive sleep apnea syndrome and hypertension: mechanism of the linkage and 24-h blood pressure control. Hypertens Res 2009; 32: 537-541.

22. Hla KM, Young T, Finn L, Peppard PE, Szklo-Coxe M, Stubbs M: Longitudinal association of sleep-disordered breathing and nondipping of nocturnal blood pressure in the Wisconsin Sleep Cohort Study. Sleep 2008; 31: 795800 .

23. Japanese Society of Hypertension: Guidelines for the Management of Hypertension, 2014.

24. Pedrosa RP, Drager LF, Gonzaga CC, Sousa MG, de Paula LK, Amaro AC, Amodeo C, Bortolotto LA, Krieger EM, Bradley TD, Lorenzi-Filho G: Obstructive sleep apnea: The most common secondary cause of hypertension associated with resistant hypertension. Hypertension 2011; 58: 811-817.

25. Javaheri S, Barbe F, Campos-Rodriguez F, Dempsey JA, Khayat R, Javaheri S, Malhotra A, Martinez-Garcia MA, Mehra R, Pack AI, Polotsky VY, Redline S, Somers VK: Sleep Apnea: Types, Mechanisms, and Clinical Cardiovascular Consequences. J Am Coll Cardiol 2017; 69: 841-858.

26. Martínez-García MA, Capote F, Campos-Rodríguez F, Lloberes P, Díaz de Atauri MJ, Somoza M, Masa JF, González M, Sacristán L, Barbé F, Durán-Cantolla J, Aizpuru F, Mañas E, Barreiro B, Mosteiro M, Cebrián JJ, de la Peña M, García-Río F, Maimó A, Zapater J, Hernández C, Grau SanMarti N, Montserrat JM; Spanish Sleep Network: Effect of CPAP on blood pressure in patients with obstructive sleep apnea and resistant hypertension: the HIPARCO randomized clinical trial. JAMA 2013; 310: 24072415.

27. Chaouat A, Weitzenblum E, Krieger J, Oswald M, Kessler R: Pulmonary hemodynamics in the obstructive sleep apnea syndrome. Results in 220 consecutive patients. Chest 1996; 109: 380-386.

28. Marin JM, Agusti A, Villar I, Forner M, Nieto D, Carrizo SJ, Barbé F, Vicente E, Wei Y, Nieto FJ, Jelic S: Association between treated and untreated obstructive sleep apnea and risk of hypertension. JAMA 2012; 307: 2169-2176.

29. JCS Joint Working Group: Guidelines for Treatment of Pulmonary Hypertension (JCS 2012). 2012. http://ww w.j-circ.or.jp/guideline/pdf/JCS2012_nakanishi_h.pdf. Accessed Dec 182017.

30. Barbé F, Durán-Cantolla J, Sánchez-de-la-Torre M, Martínez-Alonso M, Carmona C, Barceló A, Chiner E, Masa JF, Gonzalez M, Marín JM, Garcia-Rio F, Diaz de Atauri J, Terán J, Mayos M, de la Peña M, Monasterio C, del Campo F, Montserrat JM; Spanish Sleep And Breathing Network: Effect of continuous positive airway pressure on the incidence of hypertension and cardiovascular events in nonsleepy patients with obstructive sleep apnea: a randomized controlled trial. JAMA 2012; 307: 21612168.

31. Javaheri S, Javaheri S, Javaheri A: Sleep apnea, heart failure and pulmonary hypertension. Curr Heart Fail Rep 2013; 10: 315-320.

32. Bradley TD, Phillipson EA: Pathogenesis and pathophysiology of the obstructive sleep apnea syndrome. Med Clin North Am 1985; 69: 1169-1185.

33. Minic M, Ryan CM: Significance of obstructive sleep ap- nea in the patient with pulmonary hypertension. Curr Opin Pulm Med 2015; 21: 569-578.

34. Sajkov D, Wang T, Saunders NA, Bune AJ, Mcevoy RD: Continuous positive airway pressure treatment improves pulmonary hemodynamics in patients with obstructive sleep apnea. Am J Respir Crit Care Med 2002; 165: 152158.

35. Sajkov D, McEvoy RD: Obstructive sleep apnea and pulmonary hypertension. Prog Cardiovasc Dis 2009; 51: 363370.

36. Alchanatis M, Tourkohoriti G, Kakouros S, Kosmas E, Podaras S, Jordanoglou JB: Daytime pulmonary hypertension in patients with obstructive sleep apnea: the effect of continuous positive airway pressure on pulmonary hemodynamics. Respiration 2001; 68: 566-572.

37. Schäfer H, Koehler U, Ewig S, Hasper E, Tasci S, Lüderitz B: Obstructive sleep apnea as a risk marker in coronary artery disease. Cardiology 1999; 92: 79-84.

38. Yumino D, Tsurumi Y, Takagi A, Suzuki K, Kasanuki H: Impact of obstructive sleep apnea on clinical and angiographic outcomes following percutaneous coronary intervention in patients with acute coronary syndrome. Am J Cardiol 2007; 99: 26-30.

39. Punjabi NM, Shahar E, Redline S, Gottlieb DJ, Givelber R, Resnick HE; Sleep Heart Health Study Investigators: Sleep-disordered breathing, glucose intolerance, and insulin resistance: the Sleep Heart Health Study. Am J Epidemiol 2004; 160: 521-530.

40. Peker Y, Glantz H, Eulenburg C, Wegscheider K, Herlitz J, Thunström E: Effect of Positive Airway Pressure on Cardiovascular Outcomes in Coronary Artery Disease Patients with Nonsleepy Obstructive Sleep Apnea. The RICCADSA Randomized Controlled Trial. Am J Respir Crit Care Med 2016; 194: 613-620.

41. Cowie MR: Sleep apnea: State of the art. Trends Cardiovasc Med 2017; 27: 280-289.

42. Sin DD, Fitzgerald F, Parker JD, Newton G, Floras JS, Bradley TD: Risk factors for central and obstructive sleep apnea in 450 men and women with congestive heart failure. Am J Respir Crit Care Med 1999; 160: 1101-1106.

43. Javaheri S, Parker TJ, Liming JD, Corbett WS, Nishiyama $\mathrm{H}$, Wexler L, Roselle GA: Sleep apnea in 81 ambulatory male patients with stable heart failure. Types and their prevalences, consequences, and presentations. Circulation 1998; 97: 2154-2159.

44. Oldenburg O, Lamp B, Faber L, Teschler H, Horstkotte D, Töpfer V: Sleep-disordered breathing in patients with symptomatic heart failure: a contemporary study of prevalence in and characteristics of 700 patients. Eur J Heart Fail 2007; 9: 251-257.

45. Lanfranchi PA, Somers VK, Braghiroli A, Corra U, Eleuteri E, Giannuzzi P: Central sleep apnea in left ventricular dysfunction: prevalence and implications for arrhythmic risk. Circulation 2003; 107: 727-732.

46. Shamsuzzaman AS, Gersh BJ, Somers VK: Obstructive sleep apnea: implications for cardiac and vascular disease. JAMA 2003; 290: 1906-1914.

47. Kasai T, Motwani SS, Yumino D, Mak S, Newton GE, Bradley TD: Differing relationship of nocturnal fluid shifts to sleep apnea in men and women with heart failure. Circ Heart Fail 2012; 5: 467-474.

48. Tkacova R, Niroumand M, Lorenzi-Filho G, Bradley TD: Overnight shift from obstructive to central apneas in patients with heart failure: role of $\mathrm{PCO}_{2}$ and circulatory delay. Circulation 2001; 103: 238-243.

49. Nakamoto T: Sleep-disordered breathing in patients with 
cardiovascular diseases, especially hypertension and heart failure: Its clinical impacts and Treatment. Ther Res 2014; 35: 101-108.

50. White LH, Bradley TD: Role of nocturnal rostral fluid shift in the pathogenesis of obstructive and central sleep apnoea. J Physiol 2013; 591: 1179-1193.

51. Naughton MT: Cheyne-Stokes respiration: friend or foe? Thorax 2012; 67: 357-360.

52. Somers VK, Dyken ME, Clary MP, Abboud FM: Sympathetic neural mechanisms in obstructive sleep apnea. J Clin Invest 1995; 96: 1897-1904.

53. Kaneko Y, Floras JS, Usui K, Plante J, Tkacova R, Kubo T, Ando S, Bradley TD: Cardiovascular effects of continuous positive airway pressure in patients with heart failure and obstructive sleep apnea. N Engl J Med 2003; 348: 1233-1241.

54. Kasai T, Narui K, Dohi T, Yanagisawa N, Ishiwata S, Ohno M, Yamaguchi T, Momomura S: Prognosis of patients with heart failure and obstructive sleep apnea treated with continuous positive airway pressure. Chest 2008; 133: 690-696.

55. Sasayama S, Izumi T, Matsuzaki M, Matsumori A, Asanoi H, Momomura S, Seino Y, Ueshima K; CHF-HOT Study Group: Improvement of quality of life with nocturnal oxygen therapy in heart failure patients with central sleep apnea. Circ J 2009; 73: 1255-1262.

56. Nakao YM, Ueshima K, Yasuno S, Sasayama S: Effects of nocturnal oxygen therapy in patients with chronic heart failure and central sleep apnea: CHF-HOT study. Heart Vessels 2016; 31: 165-172.

57. Bradley TD, Logan AG, Kimoff RJ, Sériès F, Morrison D, Ferguson K, Belenkie I, Pfeifer M, Fleetham J, Hanly P, Smilovitch M, Tomlinson G, Floras JS; CANPAP Investigators: Continuous positive airway pressure for central sleep apnea and heart failure. N Engl J Med 2005; 353: 2025-2033.

58. Naughton MT, Rahman MA, Hara K, Floras JS, Bradley TD: Effect of continuous positive airway pressure on intrathoracic and left ventricular transmural pressures in patients with congestive heart failure. Circulation 1995; 91: 1725-1731.

59. Takano T, Endo T, Tanaka K, Seino Y, Nitta T, Matsuyama $\mathrm{Y}$, Koh M, Hayakawa H: Effects of positive endexpiratory pressure ventilation and extracorporeal ultrafiltration method in patients with refractory heart failure. Jpn Circ J 1986; 50: 359-367.

60. The Japanese Circulation Society: Statement for proper use of ASV in patients with heart failure. 2nd edition. 2016 update. Available from: http://www.j-circ.or.jp/infor mation/ASV_tekiseiriyou_rep2.pdf Accessed Dec 182017.

(Received, September 14, 2017)

(Accepted, January 15, 2018) 